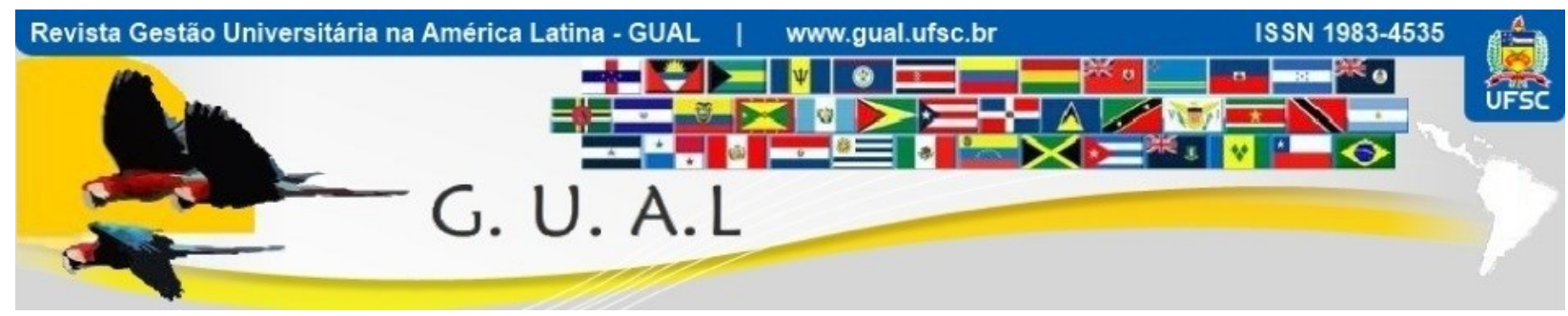

DOI: http://dx.doi.org/10.5007/1983-4535.2013v6n4p190

\title{
A DESREGULAMENTAÇÃO E A ABERTURA DA EDUCAÇÃO SUPERIOR À CONCORRÊNCIA INTERNACIONAL: AMEAÇA OU OPORTUNIDADE?
}

\author{
DEREGULATION AND OPENING OF HIGHER EDUCATION TO THE \\ INTERNATIONAL COMPETITION: THREAT OR OPPORTUNITY?
}

Annor da Silva Junior, Doutor annorsj@gmail.com

Universidade Federal do Espírito Santo - UFES

Priscilla de Oliveira Martins-Silva, Doutora

priscillamartinssilva@gmail.com

Universidade Federal do Espírito Santo - UFES

Recebido em 29/novembro/2013

Aprovado em 29/novembro/2013

Sistema de Avaliação: Double Blind Review

Esta obra está sob uma Licença Creative Commons Atribuição-Uso. 


\title{
A DESREGULAMENTAÇÃO E A ABERTURA DA EDUCAÇÃO SUPERIOR À CONCORRÊNCIA INTERNACIONAL: AMEACCA OU OPORTUNIDADE? \\ DOI: http://dx.doi.org/10.5007/1983-4535.2013v6n4p190
}

\begin{abstract}
RESUMO
Este ensaio teórico tem como tema central a regulamentação da educação superior no Brasil e a atuação das Instituições de Educação Superior (IES) nesse setor. Trata-se de uma análise ambiental tendo como fundamento a perspectiva institucionalista social e econômica. A educação superior tem passado por grandes transformações, tornando-se um dos setores mais importantes para a economia brasileira. A regulamentação educacional é vista como a forma encontrada pelos governos nacionais, para manter o controle sobre o setor, legitimando papéis, normas e valores, assegurando a funcionalidade do sistema. Na conjuntura de uma economia globalizada como a brasileira, percebe-se que o sistema educacional superior está sofrendo pressões da comunidade educacional internacional, que via Organização Mundial do Comércio (OMC), vem clamando pela desregulamentação governamental e pela abertura do setor à concorrência internacional. Diante desse cenário, em que instituições e organizações internacionais demonstram interesse em ingressar nesse setor, é que se discute os impactos que uma possível desregulamentação governamental e a consequente abertura da educação superior à concorrência internacional causaria no setor como um todo e para as IES brasileiras em particular.
\end{abstract}

Palavras-chave: Educação Superior. Regulamentação. Desregulamentação. Instituição de Educação Superior.

\begin{abstract}
This theoretical essay focuses on the regulation of higher education in Brazil and the activity of the Higher Education School (HES) in this sector. It is an environmental analysis based on the social and economic institutionalism perspective. Higher education has undergone major transformations, becoming one of the most important sectors on Brazilian economy. The regulation of education, such as legitimizing roles, norms and values, ensuring the functionality of the system, is used by national governments as a way to maintain control over the sector. In the context of a globalized economy like the Brazilian economy, it was observed that the higher education system is under pressure from the international educational community, which saw the World Trade Organization (WTO), as the way to cry out for government deregulation and the opening of the sector to international competition. In this scenario, in which international institutions and organizations show interest in joining this sector, it is discussed the impacts of a possible government deregulation and the consequent opening of higher education to international competition would cause to the sector as a whole and in particular to Brazilian HES.
\end{abstract}

Keywords: Higher Education, Regulation, Deregulation, Higher Education Schools. 


\section{A DESREGULAMENTAÇÃO E A ABERTURA DA EDUCAÇÃO SUPERIOR À CONCORRÊNCIA

\section{INTRODUÇÃO}

Pretende-se com este ensaio teórico estabelecer uma análise ambiental sobre a educação superior brasileira, mais especificamente sobre a regulamentação do setor e a pressão de organismos e instituições internacionais via Organização Mundial do Comércio (OMC) para que o governo brasileiro empreenda um processo de desregulamentação (BORGES, 2012; BORGES, 2009; WTO, 2008; DIAS, 2003). Com a desregulamentação, teríamos a abertura do setor ao mercado internacional e, consequentemente, o ingresso e a atuação de instituições educacionais estrangeiras no Brasil. As análises e reflexões, aqui realizadas, terão como escopo central as consequências que uma possível abertura da educação superior brasileira à concorrência internacional causaria no setor em geral e para as Instituições de Educação Superior (IES) brasileiras em particular. Para isso, inicia-se a discussão fazendo um breve resgate histórico da educação superior brasileira e a tradição regulamentadora que vem desde o período colonial (CUNHA, 2000; 1999).

Ao longo da história, a educação superior no Brasil, tem sido objeto de regulamentações dos governos nacionais. No período colonial, a Coroa Portuguesa tinha como política o desincentivo e proibição da criação de Instituições de Educação Superior (IES), vindo a mudar de posicionamento somente em 1.808 quando o rei D. João VI e a corte se transferiram para o Brasil. Apenas após a promulgação da república em 1889 é que o governo republicano empreendeu os primeiros esforços para a implantação da educação superior no Brasil, sendo que as primeiras universidades foram criadas na década de 1920 (CUNHA, 2000; 1999).

Durante todo esse período até a década de 1960 a política era de expansão da educação superior pública, principalmente em função do processo de federalização e do incentivo dado às universidades federais no regime militar, inclusive no nível da pós-graduação. Porém, após a criação do Conselho Federal de Educação (CFE), constituído em sua maioria por dirigentes de IES privadas, o qual pôs fim ao processo de federalização e articulou o afrouxamento das normas de criação de cursos, a ampliação de vagas e concessão do status universitário às instituições privadas, a política governamental é alterada, desta vez incentivando a expansão da educação superior privada (CUNHA, 2000; 1999).

A política pública identificada como um processo velado de "privatização" (entendido aqui como o processo em que o poder público adota política de redução da oferta de vagas nas IES públicas e ampliação da oferta de vagas pela iniciativa privada) teve início a partir da 


\section{A DESREGULAMENTAÇÃO E A ABERTURA DA EDUCAÇÃO SUPERIOR À CONCORRÊNCIA INTERNACIONAL: AMEACCA OU OPORTUNIDADE? \\ DOI: http://dx.doi.org/10.5007/1983-4535.2013v6n4p190}

metade da década de 1990, impulsionado pelas recomendações para a educação superior do Banco Mundial e da Organização das Nações Unidas para a Educação, a Ciência e a Cultura (UNESCO) (CATANI; OLIVEIRA, 2002). Essas políticas implementadas no Governo Fernando Henrique Cardoso, que trataram de flexibilizar o processo de credenciamento de IES privadas, culminaram no crescimento do setor privado sem precedentes na história. No início do ano 2000 o setor privado chegou a representar $85 \%$ do quantitativo de IES e $67 \%$ do total de matrículas na educação superior (INEP, 2001).

Aparentemente, orientação "privatizadora" da educação superior brasileira foi seguida pelos governos do Partido dos Trabalhadores (PT), ao se observar que no último censo divulgado, qual seja, o Censo da Educação Superior de 2011 verifica-se um aumento nesses indicadores que dão conta que $89 \%$ do quantitativo de 2.314 IES é constituído por instituições privadas e que $73 \%$ do total de 6.736 .689 matrículas (presencial e a distância) encontram-se no setor privado (INEP, 2013).

$\mathrm{O}$ crescimento do setor educacional brasileiro e as políticas públicas de incentivo à expansão do setor privado têm chamado a atenção e despertado o interesse de instituições estrangeiras com atuação internacional em investirem no Brasil. Porém, essas instituições estrangeiras vêm enfrentando um obstáculo: a regulamentação governamental (SILVA JUNIOR; MUNIZ, 2004). A regulamentação governamental na educação superior analisada neste ensaio sob o ponto de vista da análise ambiental e organizacional (perspectivas institucionalista social e econômica) tem sido considerada a principal barreira de entrada de instituições estrangeiras e, consequentemente, servido de um instrumento de proteção à atuação das IES brasileiras.

A proposta do presente ensaio é analisar as possíveis consequências e impactos que a desregulamentação governamental, bem como a abertura da educação superior para a concorrência internacional causariam ao setor como um todo e em particular para as IES brasileiras. Para isso, estruturou-se o ensaio em cinco partes além da introdução. A primeira discute a perspectiva institucionalista na análise ambiental e organizacional; a segunda o papel da OMC no cenário internacional; a terceira a regulamentação da educação superior; a quarta faz uma análise dos impactos da desregulamentação e da consequente abertura do setor à concorrência internacional, tendo como pano de fundo o processo semelhante ocorrido com a indústria automobilística brasileira; e a quinta e última parte apresenta-se as considerações finais. 


\section{A DESREGULAMENTAÇÃO E A ABERTURA DA EDUCAÇÃO SUPERIOR À CONCORRÊNCIA \\ INTERNACIONAL: AMEACCA OU OPORTUNIDADE? \\ DOI: http://dx.doi.org/10.5007/1983-4535.2013v6n4p190}

\section{A PERSPECTIVA INSTITUCIONALISTA NA ANÁLISE AMBIENTAL E ORGANIZACIONAL}

No contexto da teoria organizacional diversas são as perspectivas de análise ambiental e organizacional. O campo de estudo da teoria organizacional é visto como disperso e fragmentado, em que uma grande diversidade de enfoques, abordagens e ênfases são utilizadas, transformando a análise organizacional em um campo historicamente contestado (REED, 1999; BASTOS, et al, 2004).

Diante desse quadro em que múltiplas perspectivas e possibilidades analíticas se apresentam como possíveis, a visão institucionalista tem sido utilizada como uma das alternativas mais abrangentes para a análise ambiental e organizacional. A abrangência da perspectiva institucionalista se justifica em razão de considerar o ambiente, ou seja, a sociedade como uma rede, um tecido de instituições, organizações, estabelecimentos, agentes e práticas, em que processos sociais, econômicos, políticos, religiosos, entre outros se articulam simultaneamente.

$\mathrm{Na}$ perspectiva institucionalista considerada como uma abordagem sistêmica, dois conceitos são relevantes: instituições e organizações. Segundo Schvarstein (1995) as instituições representam corpos normativos de natureza cultural e jurídica integrados por idéias, valores, crenças e leis que determinam as formas de interação social. Trata-se de um nível da realidade social que define o que está estabelecido, o conjunto de normas e valores que são dominantes e que estabelecem os papéis que sustentam a ordem social. É considerado um conceito abstrato em que o que é instituído apresenta uma pretensão de universalidade, de perenidade, de verdade que possui força conservadora.

Já o conceito de organização representa o suporte material das instituições, ou seja, o lugar onde os corpos normativos (cultural e jurídico) se materializam e exercem seus efeitos sobre os indivíduos. Em outros termos, as organizações apresentam-se como mediadoras da relação entre as instituições e os indivíduos (SCHVARSTEIN; 1995).

Dada a amplitude e abrangência da perspectiva institucionalista, Bastos et al. (2004) a dividem em dois polos: de análise sociológica, denominada de neoinstitucionalismo; e, de análise econômica, denominada de economia institucional. O campo neoinstitucioalista divide-se em duas correntes: da sociologia francesa e da sociologia anglo-saxônica. $\mathrm{Na}$ vertente da francesa, representada por autores como Georges Lapassade e Michel Crozier, algumas contribuições são tidas como importante para o viés institucionalista, merecendo 


\section{A DESREGULAMENTAÇÃO E A ABERTURA DA EDUCAÇÃO SUPERIOR À CONCORRÊNCIA INTERNACIONAL: AMEACA OU OPORTUNIDADE? \\ DOI: http://dx.doi.org/10.5007/1983-4535.2013v6n4p190}

destaque: (a) sobrelevar a existência de conflitos dentro das organizações; (b) elaborar a visão das organizações com sistemas de competição e de cooperação; (c) adotar o entendimento das relações sociais como relações de poder de conotação relacional; entre outras. Na vertente anglo-saxônica, representada por autores como Philip Selznick, Paul DiMaggio e Wood Powel, as principais contribuições são: (a) contestar a visão do ator organizacional, cujas ações traduzem-se exclusivamente, em escolhas racionais e eficientes, atribuindo, em grande parte, aos fatores isomórficos a confrontação das estruturas e o direcionamento da ação; (b) apontar que a mudança organizacional não está necessariamente ligada à busca da eficiência; (c) enfatizar que as organizações participam de processos que aumentam suas similaridades e suas chances de sobrevivência sem necessariamente tornarem-se mais eficientes; e, (d) ampliar a dimensão do ambiente, espacial e temporalmente, não se concentrando apenas em influências próximas e presentes (BASTOS, et al., 2004).

O campo da economia institucional que, apresenta fronteiras de difícil delimitação, pode ser dividida em duas principais vertentes: (a) a velha economia institucional, que estuda as instituições de forma ampla, com forte ênfase em aspectos históricos e ligações com outros campos dentro das ciências sociais, tendo como principais autores Thorstein Veblen e John R. Commons; e, (b) a nova economia institucional, que estuda as estruturas de governança, com embasamento na teoria dos direitos de propriedade e na Economia dos Custos de Transação (ECT), tendo como principais autores Oliver Williamson e Douglas C. North (BASTOS, et al., 2004).

Cada um dos pólos com suas vertentes institucionalistas possuem pressupostos teóricos caracterizados pela ampla heterogeneidade, visto como um fator de riqueza e não de fragilidade teórica (SAMUELS, 1995). Essa característica da perspectiva institucionalista não permite unificar essa multiplicidade de abordagens sob um único corpo teórico, o que contrariaria a própria natureza institucionalista.

A proposta do presente ensaio é utilizar algumas dessas vertentes institucionalistas para analisar o setor educacional brasileiro e os possíveis riscos que uma possível desregulamentação e abertura à concorrência internacional traria ao setor como um todo e em particular para as IES. Por essa via, será adotado na análise o "Modelo de Era" (LENZ; ENGLENDOW, 1986). Nesse modelo, o ambiente representa um conjunto de estruturas sociais, valores e definições de papéis que caracterizam um determinado período de tempo. A mudança ocorre através de um processo de três fases: (1) a ordem existente; (2) transição 


\section{A DESREGULAMENTAÇÃO E A ABERTURA DA EDUCAÇÃO SUPERIOR À CONCORRÊNCIA INTERNACIONAL: AMEACCA OU OPORTUNIDADE? \\ DOI: http://dx.doi.org/10.5007/1983-4535.2013v6n4p190}

turbulenta; e (3) nova ordem. Em outros termos, a "Era" é um período de tempo marcado por um caráter distintivo, que descreve as mudanças ambientais em termos de três fases sucessivas: a ordem vigente; um período de transição turbulenta; e o desenvolvimento de uma ordem diferente. O que os autores chamam de "Modelo de Era" tem por finalidade descrever os ambientes organizacionais em seu sentido mais amplo, como um contexto de estruturas institucionais, papéis sociais e valores humanos. Apesar das variações na terminologia, a principal característica deste modelo é a suposição de que os padrões de arranjos institucionais e os valores de uma sociedade são dependentes de certas características estruturais subjacentes (LENZ; ENGLENDOW, 1986).

Para os autores, nesse modelo, as previsões sobre as características futuras do ambiente são realizadas por especialistas e/ou de empresas de consultoria, permitindo, com isso, adquirir algum nível de conhecimento sobre o seu ambiente e as suas tendências (LENZ; ENGLENDOW, 1986). É seguindo a perspectiva do "Modelo de Era" e as três fases do processo de mudança ambiental que este ensaio encontra fundamento e orientação.

\section{A EDUCAÇÃO SUPERIOR BRASILEIRA NA PERSPECTIVA INSTITUCIONALISTA}

Ao se analisar a educação superior brasileira pela perspectiva institucionalista, tornase fundamental distinguir duas dimensões fundamentais presentes nesse contexto: das instituições e das organizações. Na dimensão institucional, a educação superior corresponde a um conjunto combinado de instituições, que equivalem a uma árvore de decisões lógicas que regulam as atividades desse setor, indicando o que é permitido, o que é proibido e o que é indiferente fazer. Trata-se de uma dimensão abstrata, constituída por corpos normativos que determinam as formas de intercâmbio e de interação social (SCHVARSTEIN, 1995; BASTOS, et al., 2004).

Dado o grau de formalismo e de objetivação presente na educação superior brasileira, a função reguladora dessa árvore de decisões, constitui um complexo sistema de normas jurídicas que integra a Constituição Federal; a Lei de Diretrizes e Bases da Educação Nacional (LDB) e demais dispositivos legais e infralegais (leis, decretos, portarias, resoluções, pareceres, etc.) que regulamentam o funcionamento do setor.

$\mathrm{Na}$ dimensão organizacional, a educação superior corresponde a um conjunto de organizações que representa o suporte material das instituições, o espaço social em que a dimensão institucional se materializa e exerce seus efeitos sobre os indivíduos 


\section{A DESREGULAMENTAÇÃO E A ABERTURA DA EDUCAÇÃO SUPERIOR À CONCORRÊNCIA INTERNACIONAL: AMEACA OU OPORTUNIDADE? \\ DOI: http://dx.doi.org/10.5007/1983-4535.2013v6n4p190}

(SCHVARSTEIN, 1995). Essas organizações desempenham os papéis de agentes reguladores e fiscalizadores como é o caso do Ministério da Educação (MEC) e demais órgãos que compõem a sua estrutura administrativa; e de agentes executores como é o caso das IES, sejam elas de natureza pública ou privada (com e sem finalidade lucrativa). Além dessas, diversas outras organizações atuam direta ou indiretamente no contexto da educação superior brasileira, como por exemplo, os sindicatos de entidades mantenedoras, sindicatos representantes de estabelecimentos de educação privada, sindicato de professores e diretórios de estudantes.

$\mathrm{Na}$ visão institucionalista, o setor educacional superior brasileiro corresponde a uma rede de relacionamentos, em que, simultaneamente, diversas instituições (educação, saúde, trabalho, justiça, sexualidade - conceitos de nível abstrato) se relacionam com uma multiplicidade de organizações (MEC, universidades, faculdades isoladas, sindicatos - no nível do concreto), agentes e práticas. Em termos práticos, pode-se exemplificar, que uma universidade (organização) não apenas materializa os aspectos prescritos pela instituição educação (papéis instituídos de professor e aluno, modos instituídos de práticas profissionais e desempenho); como também a instituição trabalho (salário para o corpo docente e técnicoadministrativo, horários de trabalho); a instituição tempo livre (o que fazer nos horários de descanso); entre outras. Essas diversas instituições determinam as interações sociais ali estabelecidas, numa espécie de atravessamento, ou seja, na simultaneidade de ocorrências institucionais (culturais, religiosas, econômicas, políticas, entre outras) num mesmo espaço organizacional, neste caso, uma universidade (SCHVARSTEIN, 1995).

Dessa forma, percebe-se que o relacionamento entre as instituições e as organizações se processa por meio de determinação recíproca, visto que, de um lado, as instituições limitam e condicionam a autonomia das organizações; e de outro as organizações cumprem um papel institucional, ao modificar aquilo que é socialmente instituído (SCHVARSTEIN; 1995). Esse movimento de mudança, segundo o "Modelo de Era" (LENZ; ENGLENDOW, 1986) envolve três etapas, sendo, (1) a primeira caracterizada pela ordem vigente, ou seja, contexto de estruturas institucionais, papéis sociais e valores humanos que, define num determinado momento, o que é permitido, o que é proibido e o que é indiferente fazer; (2) a segunda que envolve um período de transição turbulenta em que as estruturas institucionais, papéis sociais e valores humanos se encontram em processo de mudanças (motivados pelo relacionamento entre as instituições e as organizações); (3) a terceira em que uma nova ordem é estabelecida 


\section{A DESREGULAMENTAÇÃO E A ABERTURA DA EDUCAÇÃO SUPERIOR À CONCORRÊNCIA \\ INTERNACIONAL: AMEACCA OU OPORTUNIDADE? \\ DOI: http://dx.doi.org/10.5007/1983-4535.2013v6n4p190}

apoiada e sustentada por estruturas institucionais, papéis sociais e valores humanos distintos (total ou parcialmente) daquele que caracteriza a ordem vigente da primeira etapa.

Dada a amplitude e a abrangência da perspectiva institucionalista, torna-se necessário fazer alguns recortes e isolar alguns aspectos analíticos, para que seja possível analisar e refletir sobre o comportamento de determinado contexto, mesmo que isso implique em uma abordagem reducionista (que pode ser considerada incompatível com a perspectiva institucional). Nesse sentido, optou-se por focalizar neste ensaio, alguns aspectos ligados ao setor educacional brasileiro e a pressão internacional (via OMC) para a abertura do setor a concorrência internacional.

\section{A REGULAMENTAÇÃO DA EDUCAÇÃO SUPERIOR BRASILEIRA}

O Estado brasileiro, visto como um complexo conglomerado de instituições e organizações, no contexto da educação superior exerce o seu papel de agente regulador, fiscalizador e corresponsável pela prestação de serviços educacionais. Por meio da articulação dos três poderes, o legislativo, o judiciário e o executivo, cada um em suas esferas de atuação, o Estado exerce o seu papel institucional de legislar, de julgar, de desenvolver e de implementar políticas públicas para a educação superior (SILVA JUNIOR; MUNIZ, 2004).

Ao desempenhar seu papel regulador, o Estado determina quem pode e quem não pode atuar no setor, a forma como cada agente deve atuar, suas responsabilidades, seus direitos, enfim, tudo o que se relaciona a atuação nesse setor. Assim, o Estado por meio do MEC e demais órgãos que compõem a sua estrutura administrativa, autorizam tanto ao poder público (instituições federais) quanto à iniciativa privada (instituições com e sem finalidade lucrativa) a atuarem na educação superior por meio do credenciamento como Instituição de Educação Superior (IES). Depois de credenciado e autorizado o funcionamento, a IES submete-se periodicamente a processos de reconhecimento de cursos, renovação de reconhecimento, recredenciamento, avaliação institucional entre outros processos e procedimentos regulamentados pelo Estado brasileiro (SILVA JUNIOR; MUNIZ, 2004).

Como consequência da regulamentação, as IES brasileiras estruturam-se como um macro sistema composto por dois subsistemas autônomos e interdependentes: (1) a entidade mantenedora que representa a estrutura de propriedade; e (2) a entidade mantida que representa a estrutura de direção. Em linhas gerais, a forma única como as IES brasileiras se estruturam, acabou por determinar uma padronização de processos e procedimentos em torno 


\section{A DESREGULAMENTAÇÃO E A ABERTURA DA EDUCAÇÃO SUPERIOR À CONCORRÊNCIA INTERNACIONAL: AMEACCA OU OPORTUNIDADE? \\ DOI: http://dx.doi.org/10.5007/1983-4535.2013v6n4p190}

das suas dinâmicas organizacional e institucional. Em outros termos, pode-se dizer que as IES possuem um mesmo padrão de relacionamento estabelecido entre a mantenedora e a mantida e um mesmo padrão de relações internas tanto no âmbito da mantenedora, quanto no âmbito da mantida (SILVA JUNIOR; MUNIZ, 2004).

Essas características genéricas em comum da estrutura e da dinâmica presentes nas IES brasileiras é referida como isomorfismo institucional, isso é, um processo restritivo que força uma unidade numa população a parecer com as outras unidades, que enfrentam o mesmo conjunto de condições ambientais (DIMAGGIO; POWELL, 1983). Segundo os autores o isomorfismo institucional produz conformidade através de três mecanismos: (1) o isomorfismo coercitivo, derivado de pressões formais e informais; (2) o isomorfismo mimético, baseado na imitação e resultante de respostas às incertezas; e (3) o isomorfismo normativo, decorrente da profissionalização dos gerentes e especialistas (DIMAGGIO; POWELL, 1983). Na visão de Silva Junior e Muniz (2004) observa-se no caso das IES brasileiras a presença simultânea dos três tipos de mecanismos do isomorfismo institucional.

Esse viés regulador exercido pelo Estado brasileiro transformou a educação superior em um dos setores mais regulamentados do país. Em razão dessa ampla regulamentação governamental, percebe-se um movimento de "blindagem" da educação superior a um dos fenômenos mais abrangentes da atualidade, a globalização. O termo globalização, forjado na década de 1980 nos Estados Unidos, tinha como finalidade interpretar o processo de interdependência econômica entre os estados nacionais e entre as empresas transnacionais, transformando assim, a economia local/nacional em economia global. Esse processo de interdependência ampliou-se ao longo dos anos, e hoje a interdependência deixou de ser apenas econômica, para se tornar também política, social, cultural, religiosa, educacional, entre outras (DIAS, 2005).

O Brasil, que desde a década de 1990 no Governo Fernando Collor de Melo abriu a sua economia para o mercado internacional veio se inserindo nessa aldeia global, e, hoje diversos setores encontram-se plenamente globalizados como, por exemplo, a indústria automobilística, o setor siderúrgico, o setor energético e as telecomunicações. Todos esses setores passaram por um amplo processo de transformação institucional (LENZ; ENGLENDOW, 1986), em que as organizações que nele atuam tiveram que se tornar mais competitivas e mais avançadas tecnologicamente para atuar em outros mercados como também concorrer com empresas estrangeiras no mercado local. 


\section{A DESREGULAMENTAÇÃO E A ABERTURA DA EDUCAÇÃO SUPERIOR À CONCORRÊNCIA INTERNACIONAL: AMEACCA OU OPORTUNIDADE? \\ DOI: http://dx.doi.org/10.5007/1983-4535.2013v6n4p190}

A educação superior brasileira foi um dos poucos setores que foi excluído desse complexo processo de interdependência global. Uma das principais explicações para essa exclusão está relacionada à regulamentação governamental que, ainda não permite que a concorrência internacional atinja esse setor. Em grande parte essa "blindagem" governamental justifica-se pelos valores institucionais que fizeram parte da história da educação superior brasileira. Esses valores defendem que a educação superior deve ser tratada como um bem público e direito social por tem como finalidade essencial a formação de sujeitos e, por consequência, o aprofundamento da cidadania e da democratização da sociedade (DIAS SOBRINHO, 2013).

Segundo esses valores institucionais, a educação superior brasileira é um "bem público" e, como tal, não pode ser tratada como uma "mercadoria" a ser comercializada. Nesse contexto, a globalização é vista como um processo ameaçador a esses valores institucionais, já que a sua consequência maior seria a mercantilização da educação superior e a retirada do papel de principal protagonista na definição das políticas educacionais exercido pelo Estado.

Visando resguardar esses valores institucionais, o Estado brasileiro vem implementando o Programa de Apoio a Reestruturação e Expansão das Universidades Federais (REUNI) que tem como objetivos centrais a retomada do crescimento da educação superior pública, o fortalecimento da universidade pública, o controle da qualidade dos serviços educacionais prestados, a democratização do acesso e a construção de uma gestão mais democrática da educação superior (MEC, 2013).

Esse projeto, que consiste em um instrumento de regulamentação governamental, é visto como um meio de fortalecer o sentido de educação pública e de qualidade e impedir que a globalização chegue à educação superior, preservando com isso, as IES brasileiras (públicas e privadas) de enfrentarem a concorrência internacional.

\section{A ORGANIZAÇÃO MUNDIAL DO COMÉRCIO (OMC) NO CENÁRIO INTERNACIONAL}

A OMC é a organização internacional, sediada em Genebra na Suíça, cujo objetivo principal é a abertura do comércio para o benefício de todos. Embora essa seja sua principal missão, há diferentes maneiras de olhar para a OMC: (1) trata-se de uma organização vocacionada para a promoção da abertura do comércio em nível internacional; (2) é um fórum para que governos nacionais possam negociar acordos comerciais; (3) é um ambiente para 


\section{A DESREGULAMENTAÇÃO E A ABERTURA DA EDUCAÇÃO SUPERIOR À CONCORRÊNCIA \\ INTERNACIONAL: AMEACA OU OPORTUNIDADE? \\ DOI: http://dx.doi.org/10.5007/1983-4535.2013v6n4p190}

solução de disputas comerciais; e (4) operando em um sistema de regras comerciais, é essencialmente um espaço para que os governos membros busquem resolver os problemas comerciais que enfrentam um com o outro (WTO, 2013).

Segundo Borges (2009), a OMC se configura como organismo internacional criado com o propósito de promover a liberalização do comércio entre os países-membros nas mais diversas áreas e questões, abarcando aspectos que não se restringem apenas ao comércio de bens materiais. Segundo a autora, estão incluídas no âmbito de suas regras e negociações, áreas antes não reguladas por critérios comerciais e mercantis, tais como os serviços educacionais e os relacionados aos direitos de propriedade intelectual. Para a efetivação desses objetivos, a OMC possui personalidade jurídica desfrutada por instituições como a UNESCO (Organização das Nações Unidas para a Educação, a Ciência e Cultura) e o BIRD (Banco Internacional de Reconstrução e Desenvolvimento) - todas elas se configurando como instituições especializadas da ONU (Organização das Nações Unidas) - oferecendo à regulamentação relativa ao comércio uma estrutura organizacional que não era dada pelo GATT (General Agreement on Tariffs and Trade) (BORGES, 2009).

Até março deste ano, participavam como países membros 159 Estados Nacionais, inclusive o Brasil (WTO, 2013). Na OMC (que é considerada o único fórum internacional legítimo para discussão e solução de matérias relacionadas à regulamentação do comércio e sua liberalização em nível global) qualquer um dos 159 países-membro podem submeter as normas jurídicas e regulamentações de outro país a julgamento, desde que essa norma seja considerada como impeditivo para o desenvolvimento do comércio mundial. O julgamento e a decisão sobre essas demandas são realizadas em tribunais secretos (constituídos por painel de especialistas em comércio) e o ônus da prova cabe ao país questionado que deve provar que a norma questionada não consiste em uma restrição ao comércio, no sentido definido pela própria OMC (SIQUEIRA, 2004).

Desde o ano de 1995, quando o Brasil se tornou um país membro da OMC, foi assinado um acordo intitulado General Agreement on Trade in Services (GATS) que em português significa Acordo Geral sobre Comércio e Serviços (AGCS). Esse acordo, que tinha como proposta a liberalização progressiva dos serviços com a conclusão das negociações num prazo de 10 anos, teve como objetivo a liberalização do comércio de todo tipo de serviço, com exceção aos serviços que fossem fornecidos no exercício da autoridade governamental e que 


\section{A DESREGULAMENTAÇÃO E A ABERTURA DA EDUCAÇÃO SUPERIOR À CONCORRÊNCIA \\ INTERNACIONAL: AMEACCA OU OPORTUNIDADE? \\ DOI: http://dx.doi.org/10.5007/1983-4535.2013v6n4p190}

não sejam oferecidos de forma comercial e nem entrem em competição com um ou mais provedores de serviços (BORGES, 2009; SIQUEIRA, 2004; DIAS, 2003).

Assim, na medida em que os Estados Nacionais fossem adotando uma postura mais liberal e reduzissem a sua participação em setores que possuíam exclusividades na oferta de serviços, por meio de transferência desses serviços para a iniciativa privada, a proposta do GATS/AGCS assinada no âmbito da OMC iria se materializando e ampliando o seu escopo. Segundo Siqueira (2004), a consequência desse processo implicaria na incorporação de diversos setores tradicionalmente mantidos e regulamentados pelos Estados Nacionais, tais como educação, saúde, meio ambiente, saneamento, etc., em um ordenamento em que tivessem suas bases na lógica do lucro, da oferta e da competição, características do pensamento liberal do "livre" mercado.

Aparentemente, o caso da educação superior brasileira, se ajusta a esse contexto. As políticas públicas liberais adotadas no Governo Fernando Henrique Cardoso e nos governos do PT indicam que o Estado Brasileiro vem cumprindo o acordo assinado em 1995 (antes da promulgação da LDB) ao reduzir a participação do setor público e, consequentemente, aumentar a participação da iniciativa privada que, segundo o Censo da Educação Superior de 2011, responde por 89\% do quantitativo de IES e 73\% do total de matrículas (INEP, 2013).

Em parte, essa situação fez com que as pressões pela desregulamentação da educação superior brasileira no âmbito da OMC somente aumentasse ao longo dos anos. As pressões estão relacionadas às demandas de países centrais como Estados Unidos, Inglaterra e França, que veem no Brasil uma oportunidade de suprir a ociosidade de capacidade de oferta desse serviço em seus territórios. Uma provável desregulamentação e, a consequente abertura da educação superior ao comercio internacional, faria com que a educação superior brasileira passasse por uma ampla transformação do ponto de vista institucional: de uma concepção de educação como um bem público regulado pelo Estado, para a concepção de que a educação como uma mercadoria regulada por forças de mercado.

\section{A DESREGULAMENTAÇÃO, A ABERTURA DA EDUCAÇÃO SUPERIOR BRASILEIRA À CONCORRÊNCIA}

Internacional e os Impactos para o Setor e para as IES: Ameaça ou Oportunidade?

Antes de se iniciar essa discussão, é necessário analisar o que vem a ser a desregulamentação governamental. Para isso é necessário retomar de forma sucinta o processo inverso, ou seja, o que vem a ser a regulamentação. A regulamentação, conforme já 


\section{A DESREGULAMENTAÇÃO E A ABERTURA DA EDUCAÇÃO SUPERIOR À CONCORRÊNCIA \\ INTERNACIONAL: AMEACA OU OPORTUNIDADE? \\ DOI: http://dx.doi.org/10.5007/1983-4535.2013v6n4p190}

abordado anteriormente, refere-se à atuação do Estado como agente regulador, que por meio dos três poderes constituídos, o legislativo, o judiciário e o executivo, desenvolve e implementa o sistema de normas e regras jurídicas e políticas públicas para a educação superior.

Visto o que vem a ser a regulamentação, é possível traçar os principais aspectos relativos à desregulamentação da educação superior. Contrariamente ao que se poderia imaginar, a desregulamentação não é o abandono por parte do Governo Federal de seu papel de agente regulador, o que naturalmente criaria um universo de anomia e isso poderia levar o setor e o sistema educacional como um todo ao caos. Entende-se por desregulamentação, a flexibilização na imposição de normas e regras, deixando que o setor opere com determinado grau de liberdade, permitindo que as organizações e instituições que atuam no setor (players) tenham total liberdade para desempenhar suas funções gerenciais básicas, e, possam independente da forma jurídica como são constituídas (com ou sem finalidade lucrativa), desenvolver e implementar estrutura e dinâmica própria sem ter que assumir um isomorfismo institucional (DIMAGGIO; POWEL, 1983). A desregulamentação levaria assim, a abertura do setor para atuação de todo e qualquer tipo de instituição educacional (inclusive de outros países), que obedeceriam, a critérios e as diretrizes de caráter mais flexíveis de organização e de funcionamento da educação superior brasileira.

Porém, antes mesmo de iniciar a discussão acerca de uma possível desregulamentação, há que se refletir sobre quais seriam os fatores motivadores e os interesses da comunidade internacional em relação ao setor educacional superior brasileiro. Para nortear a reflexão, recorreu-se a um conjunto de indicadores sobre os investimentos em educação e em educação superior divulgados pela Organisation for Economic Co-operation and Development (OECD) em seu relatório intitulado "Education at a Glance 2012: OECD Indicators". Segundo a OECD (2012), no ano de 2009, os países membros da OECD investiram na média $6,0 \%$ do Produto Interno Bruto (PIB) em educação (considerando investimentos públicos e privados e em todos os níveis educacionais - educação básica e superior). Seis países tiveram investimentos superiores a $7 \%$ como foi o caso da Islândia $(8,1 \%)$, da Coréia $(8,0 \%)$, da Alemanha (7,9\%), Nova Zelândia (7,4\%), Estados Unidos da América (7,3\%) e de Israel $(7,2 \%)$. Por outro lado, seis países tiveram investimentos inferiores a 5\% do PIB em educação, como foi o caso da Itália (4,9\%), da Republica Tcheca e da Hungria $(4,8 \%)$, da Eslováquia (4,7\%), da Índia (3,5\%) e da Indonésia (3,6\%). O Brasil contou com um 


\section{A DESREGULAMENTAÇÃO E A ABERTURA DA EDUCAÇÃO SUPERIOR À CONCORRÊNCIA \\ INTERNACIONAL: AMEACA OU OPORTUNIDADE? \\ DOI: http://dx.doi.org/10.5007/1983-4535.2013v6n4p190}

investimento de 5,5\% do PIB em educação, enquanto os vizinhos da América do Sul, Argentina e Chile investiram respectivamente 7,0\% e 6,8\% (OBS: O Brasil e a Argentina não fazem parte da OECD, mas, foram incluídos no relatório por fazer parte do G-20 - grupo formado pelos ministros de finanças e chefes dos bancos centrais das 19 maiores economias do mundo mais a União Europeia).

Especificamente em relação aos investimentos em educação superior, o relatório da OECD aponta que em 2009 os países membros da OECD investiram na média 1,6\% do Produto Interno Bruto (PIB). Quatro países tiveram investimentos superiores a 2\% como foi o caso da Coréia e dos Estados Unidos da América (2,6\%) e do Chile e do Canadá (2,5\%). Por outro lado, quatro países da OECD e do G-20 tiveram investimentos inferiores a $1 \%$ do PIB em educação superior, como foi o caso da Republica da Eslováquia $(0,9 \%)$, do Brasil $(0,8 \%)$, da Indonésia $(0,7 \%)$ e da África do Sul (0,6\%). A vizinha Argentina contou com investimentos de 1,4\% do PIB em educação superior.

Os dados da OECD (2012) indicam que países como Coréia, Estados Unidos, Canadá e Chile possuem os maiores percentuais de investimentos do PIB em educação superior, enquanto que o Brasil encontra-se no grupo daqueles que ainda destinam menores investimentos do PIB neste setor. A partir dos dados e considerando o histórico da educação superior brasileira, cujos investimentos foram proibidos pela Coroa Portuguesa até o ano de 1808 e que somente iniciou um processo de transformação e evolução qualitativa e quantitativa nas décadas de 1970 e 1980 (CUNHA, 2000; 1999), pode-se inferir que a educação superior no Brasil ainda é jovem e, portanto, ainda está em processo de evolução e de alcance de maturidade. Neste caso, há oportunidades de investimentos no setor, haja vista os dados do Censo 2010 do Instituto Brasileiro de Geografia e Estatística (IBGE) que indicam que na faixa etária de 25 anos ou mais o percentual de homens com pelo menos o nível superior de graduação completo foi de $9,9 \%$, e das mulheres, de $12,5 \%$; percentuais que passavam para 11,5\% e 19,2\%, respectivamente, entre os ocupados (IBGE, 2012).

Levando em consideração os aspectos históricos (CUNHA, 2000; 1999) e os indicadores recentes (OECD, 2012; IBGE, 2012), pode-se inferir que o interesse da comunidade internacional sobre o setor educacional superior brasileiro esteja relacionado à parcela de mais de $80 \%$ da população que não possui nível superior. Aparentemente, além das questões históricas da educação superior brasileira, a elevada parcela da população ainda sem 


\section{A DESREGULAMENTAÇÃO E A ABERTURA DA EDUCAÇÃO SUPERIOR À CONCORRÊNCIA \\ INTERNACIONAL: AMEACCA OU OPORTUNIDADE? \\ DOI: http://dx.doi.org/10.5007/1983-4535.2013v6n4p190}

formação em nível superior está relacionada à uma crise de demanda (e não de necessidade) enfrentada pelo setor (SILVA JUNIOR, MARTINS, 2007).

Segundo Silva Junior e Martins (2007), enquanto, a necessidade está relacionada a uma exigência individual a ser satisfeita pelo consumo; a demanda refere-se ao consumo propriamente dito e expresso em termos quantitativos. A demanda, por possuir condicionantes como (1) preferência do consumidor; (2) poder de compra do consumidor, sem o qual a demanda não existe em termos econômicos; (3) preços dos outros bens ou serviços, tanto os substitutos quanto os complementares; (4) preço do bem ou serviço em questão, pois, pelos mecanismos comuns de mercado, quanto mais alto for o preço, menor será a quantidade demandada; (5) qualidade do bem ou serviço; e, (6) expectativas do consumidor quanto à renda pessoal e aos preços em geral (SANDRONI, 1999) tem relação direta com aspectos como poder de compra do consumidor e capacidade de oferta das organizações. No caso da educação superior brasileira, observa-se a presença de necessidade social (mais de $80 \%$ da população não possui nível superior) que não se converte em consumo pela falta de poder de compra da população ou pela incapacidade de oferta das IES que atuam no Brasil (SILVA JUNIOR; MARTINS, 2007).

Levando em consideração essas características atuais da educação superior brasileira, observa-se no cenário internacional, um movimento das instituições estrangeiras no sentido de ingressar nesse mercado via Organização Mundial do Comércio (OMC). O interesse dessas instituições está ligado de certa forma a saturação dos mercados nos países centrais (Estados Unidos, Canadá, Reino Unido, Alemanha, entre outros) e a necessidade de buscar novos mercados em países periféricos como é o caso do Brasil.

Visando enriquecer a discussão acerca de uma possível desregulamentação e abertura da educação superior em termos dos impactos desse processo para o setor como um todo e em especial para as IES, optou-se por utilizar, para efeitos de comparação, um processo semelhante (guardada as devidas proporções) vivenciado nos anos 1990 pela indústria automobilística brasileira. A utilização do caso da indústria automobilística servirá de parâmetro para que se possa fazer uma análise comparativa de possíveis consequências para a educação superior, e daí refletir se essa possível desregulamentação e abertura podem representar uma ameaça ou uma oportunidade para o setor e para as IES nacionais que nela operam. Feitas essas considerações iniciais, passa-se especificamente a discussão central deste ensaio. 


\section{A DESREGULAMENTAÇÃO E A ABERTURA DA EDUCAÇÃO SUPERIOR À CONCORRÊNCIA INTERNACIONAL: AMEACA OU OPORTUNIDADE? \\ DOI: http://dx.doi.org/10.5007/1983-4535.2013v6n4p190}

Semelhante ao que aconteceu em outros setores produtivos, como por exemplo, o da indústria automobilística, a educação superior brasileira, tende a passar, nos próximos anos, por um amplo processo de abertura de mercado, por meio do livre acesso das instituições estrangeiras, que poderão ofertar vagas em todos os níveis da educação superior, principalmente na modalidade à distância. Essa abertura de mercado, no caso da educação superior brasileira, depende em grande parte do processo de desregulamentação governamental que flexibilizará o seu funcionamento via alterações na legislação educacional.

O período econômico da história empresarial brasileira que teve início na década de 1930 e durou até o final da década de 1980, conhecido como Industrialização por Substituição de Importações (ISI), cuja economia articulava-se por meio do tripé econômico (capital estatal, capital estrangeiro e capital privado), caracterizou a indústria automobilística brasileira como um setor produtivo amplamente regulamentado. Havia reserva de mercado em que as indústrias de capital estrangeiro (Ford, General Motors, Volkswagen e Fiat) operavam em um mercado protegido, livre da concorrência externa. Durante um longo período, desde a implantação da Ford e da General Motors no Brasil em 1919 e em 1925 respectivamente, até a abertura do mercado nos anos 1990 com o Governo de Fernando Collor de Mello, esse setor operou como uma economia fechada, com a presença apenas de quatro players protegidos das ameaças da indústria automobilística de outros países. Nesse mesmo período, nos outros mercados (Estados Unidos da América e Europa) onde essas quatro indústrias operavam, o contexto era amplamente diferente, já que possuíam uma competição aberta, principalmente com as fábricas japonesas (Honda e Toyota).

O fato dessas indústrias transnacionais (Ford, General Motors, Volkswagen e Fiat), operarem em contextos amplamente diferentes, quais sejam, em mercado de economia fechada (como foi o caso brasileiro) e mercados de economia aberta (como era o caso estadunidense e europeu), fez com que as suas respectivas matrizes (sediadas nos Estados Unidos da América e na Europa) definissem políticas diferentes para cada contexto. No caso do mercado de economia aberta, a visão era de livre concorrência e evolução tecnológica, em que ano a ano, eram oferecidos ao mercado carros inovadores, mais confortáveis, mais econômicos e mais baratos. Já no caso brasileiro (economia fechada) a visão era de reserva de mercado, atraso e até paralisia tecnológica, e o que se oferecia ao mercado eram carros que o então Presidente Fernando Collor de Mello chegou a chamar de "carroças", ou seja, veículos desconfortáveis, com alto consumo de combustível e excessivamente caros (relação entre 


\section{A DESREGULAMENTAÇÃO E A ABERTURA DA EDUCAÇÃO SUPERIOR À CONCORRÊNCIA \\ INTERNACIONAL: AMEACCA OU OPORTUNIDADE? \\ DOI: http://dx.doi.org/10.5007/1983-4535.2013v6n4p190}

custo e benefícios quando comparados com os veículos existentes nos Estados Unidos da América e na Europa).

Em meados da década de 1990, quando a abertura do mercado brasileiro à economia internacional tornou-se uma realidade, as principais indústrias automobilísticas do mundo decidiram investir no Brasil. Em poucos anos, chegaram ao Brasil marcas como a Honda, a Toyota, a Renault, a Peugeot, a Audi, a BMW, entre outras. De lá par cá, o mercado automobilístico brasileiro, transformou-se radicalmente, a competição fez com que as indústrias desenvolvessem veículos cada vez melhores, avançados tecnologicamente e mais baratos.

Percebeu-se nesse movimento de evolução tecnológica, que as indústrias pioneiras em termos de mercado brasileiro (Ford, General Motors, Volkswagen e Fiat) não tiveram dificuldade em se ajustar, pois, já enfrentavam essa realidade competitiva nos mercados estadunidense e europeu. Isso fez com que, de certa forma, a população brasileira enfrentasse o processo de abertura de mercado de forma positiva, sem problemas de abastecimento e de crise no setor (tanto em termos de produção, como em termos de serviços de assistência de pós-venda e de oficina de reparos). Destaca-se, porém, que o setor enfrentou problemas de outras naturezas, como por exemplo, as alterações na dinâmica da força de trabalho, a redução de empregos, entre outros fatores que, de maneira mais ampla, não tiveram implicações em termos de descontinuidade na produção e na prestação de serviços no setor (desabastecimento).

E no caso da educação superior brasileira? O que acontecerá com esse setor econômico? Como as Instituições de Educação Superior (IES) enfrentarão a concorrência internacional? A abertura do mercado e o ingresso de IES estrangeiras trarão melhoria na qualidade dos serviços educacionais prestados? Essa abertura representa uma ameaça ou uma oportunidade?

Esses são apenas alguns questionamentos que a comunidade acadêmica brasileira precisa fazer. Para muitos desses questionamentos ainda não se têm respostas, porém já são o suficiente para se pensar ou repensar o modelo de educação superior no Brasil.

Em razão da ampla regulamentação, em que o Governo Federal apresenta-se como o grande responsável pela operacionalização e controle do sistema, as IES operam segundo critérios que limitam a sua forma de constituição, a sua estrutura e sua dinâmica, além de 


\section{A DESREGULAMENTAÇÃO E A ABERTURA DA EDUCAÇÃO SUPERIOR À CONCORRÊNCIA \\ INTERNACIONAL: AMEACA OU OPORTUNIDADE? \\ DOI: http://dx.doi.org/10.5007/1983-4535.2013v6n4p190}

inibirem sua autonomia gerencial e limitarem seu campo de atuação a uma jurisdição específica (SILVA JUNIOR; MUNIZ, 2004).

Essas características da educação superior brasileira fazem com que as instituições operem com um reserva de mercado, onde os players são limitados e conhecidos uns dos outros, a concorrência seja menor e limitada no setor. Nesse contexto, a questão da qualidade dos serviços educacionais prestados pode ser questionada, e tem levado a comunidade acadêmica e a estrutura administrativa do MEC, a pensar e repensar o sistema como um todo. Esse processo vem sendo discutido desde o governo Fernando Henrique Cardoso, que implementou de forma sistemática a avaliação do sistema, como uma maneira de medir a qualidade da educação superior no Brasil.

Voltando aos questionamentos feitos anteriormente, percebe-se que diferentemente do setor automobilístico, as IES brasileiras (públicas e privadas), em razão de não possuírem experiências em mercados de concorrência perfeita, terão dificuldades de adaptação em relação à concorrência internacional. As públicas por serem mais burocráticas e dependerem de recursos do governo, e as privadas por serem vocacionadas quase que exclusivamente para as atividades de ensino, estarão enfrentando instituições privadas estrangeiras ágeis do ponto de vista gerencial, tradicionalmente vocacionadas para o ensino, a pesquisa e a extensão, vinculadas a grandes grupos econômicos que possuem meios para financiamento da educação superior.

Comparando as instituições brasileiras com as estrangeiras, pode-se perceber consideráveis diferenças em termos de tradição (tempo de atuação na educação superior), da prática educativa (atividades de ensino, de pesquisa e de extensão), de desenvolvimento de educação a distância e de atuação internacional. No que se refere a tradição, enquanto a primeira universidade brasileira (reconhecida como tal pela comunidade acadêmica) foi a Universidade do Brasil criada em 1920 (hoje conhecida como Universidade Federal do Rio de Janeiro), no caso europeu, observa-se, por exemplo a presença de universidades fundadas no Século XV e Século XVI (quando o Brasil foi descoberto) como é o caso das universidades espanholas Universidad Complutense de Madrid (1499) e Universidad de Granada (1531).

Quando o critério de comparação é a prática educativa, ou seja, quando considera-se as três atividades ligadas à educação superior (ensino, pesquisa e extensão), percebe-se no contexto brasileiro, que a grande maioria das instituições (notadamente as privadas) dedicamse e investem prioritariamente no ensino, ou seja, na transmissão do conhecimento. Vale aqui 


\section{A DESREGULAMENTAÇÃO E A ABERTURA DA EDUCAÇÃO SUPERIOR À CONCORRÊNCIA \\ INTERNACIONAL: AMEACA OU OPORTUNIDADE? \\ DOI: http://dx.doi.org/10.5007/1983-4535.2013v6n4p190}

considerar que as atividades de pesquisa e extensão são desenvolvidas no Brasil, porém, quase que exclusivamente nas universidades públicas, que são minoria no sistema educacional superior (INEP, 2013).

Como a grande maioria das instituições brasileiras é privada, o impacto que as atividades de pesquisa e extensão geram para a qualidade do sistema como um todo é irrelevante. De certa forma, essa vocação para o ensino da educação superior brasileira pode ser explicada historicamente. Desde o surgimento da educação superior, a política portuguesa era de incentivar apenas a transmissão do conhecimento, em que o professor era o detentor de conhecimento e de experiências profissionais que tinha como preocupação central a sua transmissão aos alunos que nada sabiam e nada conheciam (MASETTO, 1998). Diferentemente, na Europa e nos Estados Unidos da América, as instituições (tanto públicas quanto privadas) investem muito mais em pesquisa e extensão (por meio de recursos próprios e de subsídios financeiros de natureza pública e privada), focando fundamentalmente na criação, transformação, indagação e na aplicação do conhecimento, fazendo com que a comunidade acadêmica pense e produza o que Thomas Kuhn chamou de revolução científica. Essas características das IES brasileiras as condicionam a serem repetidoras do que se produz nos Estados Unidos da América e na Europa.

Em termos do desenvolvimento da educação a distância, observa-se que o Brasil ainda apresenta indicadores modestos. Segundo o Censo da Educação Superior de 2011, do total de $30.420(100 \%)$ cursos de graduação existentes no país, $29.376(96,6 \%)$ são ofertados na modalidade presencial e $1.044(3,4 \%)$ na modalidade a distância. Em relação ao número de alunos matriculados, do total e 6.739 .689 (100\%) de matrículas, $5.748 .955(85,3 \%)$ estão vinculados à modalidade presencial e 990.734 (14,7\%) na modalidade a distância (INEP, 2013). Os dados indicam que a educação a distância possui amplo potencial de crescimento, principalmente, quando leva-se em consideração o fato de que mais de $80 \%$ da população ainda não possui graduação. Há ainda que se observar, que as instituições estrangeiras possuem tecnologia e capacidade instalada para explorar esse tipo de modalidade educacional a partir de suas matrizes localizadas em países estrangeiros.

Ao levar em consideração a questão da atuação internacional, tanto pela implantação de campus universitário em outros países (oferta de serviços educacionais na modalidade presencial) quanto pela oferta de educação à distância, verifica-se que enquanto as universidades brasileiras não possuem essa prática, isso já é comum na Europa e nos Estados 


\section{A DESREGULAMENTAÇÃO E A ABERTURA DA EDUCAÇÃO SUPERIOR À CONCORRÊNCIA \\ INTERNACIONAL: AMEACA OU OPORTUNIDADE? \\ DOI: http://dx.doi.org/10.5007/1983-4535.2013v6n4p190}

Unidos da América. As universidades estrangeiras têm desenvolvido alianças corporativas de instituições universitárias para atuação internacional (presencial e a distância) como é o caso da The University of Birmingham que é membro fundador do Universitas 21 (um grupo de elite das melhores universidades de pesquisa de todo o mundo, principalmente da Europa, Estados Unidos da América, Canadá e Ásia), e da The University of Nottingham com presença física na China (Ningbo, Provincia de Zhejiang) e na Malásia (Kuala Lumpur).

Diante desse quadro, pode-se afirmar que num primeiro momento, a abertura do mercado educacional à concorrência estrangeira representa uma ameaça, pois, as instituições brasileiras não estão preparadas para enfrentar uma competição em escala internacional com instituições tradicionais e experientes nesse tipo de concorrência.

Com a desregulamentação e a abertura do mercado à concorrência internacional, existe uma tendência de que a educação superior brasileira consolide-se como um setor exclusivamente privado, ou seja, de educação paga e com conotações eminentemente mercantilistas, o que implica em romper com toda a tradição de educação superior pública, gratuita e de bem público (DIAS SOBRINHO, 2013). De certa forma, esse aspecto pode vir a ser um grande entrave para o setor educacional, diferentemente do que ocorreu no setor automobilístico, já que na educação pode haver a ruptura total de um modelo secular de educação superior pública e gratuita.

Esse movimento implicará em uma transformação institucional em que, do ponto de vista das instituições, os corpos normativos de natureza cultural e jurídica serão revistos pela sociedade, redefinindo as formas de interações sociais vigentes, bem como os papéis das organizações como mediadoras da relação entre as instituições e os indivíduos da sociedade (SCHVARSTEIN; 1995). Esse processo de transformação, articulará três momentos distintos: (1) da ordem vigente; (2) da transição turbulenta; e (3) do estabelecimento de uma nova ordem (LENZ; ENGLENDOW, 1986).

Neste caso, há que se refletir, em que medida a sociedade brasileira está preparada para enfrentar essa transição turbulenta e quais serão os novos padrões institucionais da nova ordem. Aparentemente, esse movimento de transformação institucional foi traçado no passado, quando o Brasil ingressou com país membro da $\mathrm{OMC}$ e nos anos seguintes quando implementou as políticas públicas para a educação superior ditadas pelo Banco Mundial e pela UNESCO (CATANI; OLIVEIRA, 2002), que culminou na concretização do processo de "privatização" da educação superior brasileira. 


\section{A DESREGULAMENTAÇÃO E A ABERTURA DA EDUCAÇÃO SUPERIOR À CONCORRÊNCIA INTERNACIONAL: AMEACA OU OPORTUNIDADE? \\ DOI: http://dx.doi.org/10.5007/1983-4535.2013v6n4p190}

Não pretende-se aqui fazer apologia do fim da educação pública gratuita, mas apenas discutir e analisar essa possibilidade, já que em sendo esse os rumos da educação superior, algumas questões terão que ser repensadas, como por exemplo, o papel do estado, a criação de uma agência reguladora (como é o caso da Agência Nacional de Telecomunicações ANATEL e da Agência Nacional de Energia Elétrica - ANAEL) e o acesso à educação superior. Talvez seja necessário após a ruptura do modelo, ou seja, da desregulamentação e da abertura do mercado, instituir-se um novo sistema regulador, em que o estado não configure como um dos players do setor.

Num segundo momento, porém, a presença de universidades estrangeiras no contexto brasileiro, pode representar uma oportunidade para que o sistema educacional superior como um todo e em especial as IES desenvolvam suas habilidades e competências, deixando de ser apenas reprodutoras de conhecimento, para tornarem-se grandes instituições de pesquisa, contribuindo por meio de atividades de extensão universitária para o desenvolvimento de uma sociedade mais evoluída criticamente e comprometida com o desenvolvimento nacional. Esse salto passa fundamentalmente pela conscientização de dirigentes, de gestores universitários, de governantes e de empresários, que precisam repensar suas participações na educação superior brasileira, destinando maiores investimentos em centros de pesquisa, na formação de profissionais qualificados e na geração de novos conhecimentos.

\section{CONSIDERAÇÕES FINAIS}

A proposta do artigo foi analisar os impactos de uma possível desregulamentação e a abertura da educação superior brasileira à concorrência internacional, para o setor como um todo e em especial à IES. Dada a complexidade da proposta, buscou-se a partir de uma perspectiva histórica, compreender como se deu o surgimento e a evolução da educação superior no Brasil e como esse processo ocorreu do ponto de vista da regulação governamental. (CUNHA, 2000, 1999).

Analisou-se do ponto de vista da regulamentação como se organiza a educação superior e como se estruturam as IES privadas, enfocando também a sua dinâmica institucional, que em função da própria regulamentação acaba por determinar um isomorfismo institucional (DIMAGGIO; POWELL, 1983). Mapeou-se um terreno estrutural sob o qual as IES operacionalizam sua dinâmica institucional e como essa dinâmica está influenciada pela 


\section{A DESREGULAMENTAÇÃO E A ABERTURA DA EDUCAÇÃO SUPERIOR À CONCORRÊNCIA \\ INTERNACIONAL: AMEACCA OU OPORTUNIDADE? \\ DOI: http://dx.doi.org/10.5007/1983-4535.2013v6n4p190}

regulamentação do setor educacional superior, causando impactos nas práticas de gestão universitária (SCHVARSTEIN; 1995; LENZ; ENGLENDOW, 1986).

Levando-se em consideração o histórico da educação superior brasileira e os indicadores demográficos, econômicos e educacionais (CUNHA, 2000, 1999; OECD, 2012, IBGE, 2012; INEP, 2013) que tem despertado o interesse de instituições universitárias estrangeiras em ingressar nesse segmento, via pressão de organismos internacionais como é o caso da OMC, discutiu-se os possíveis impactos desse processo para o setor educacional como um todo e em especial para as IES que nele atuam. Realizou-se essa proposta por meio de discussões e reflexões eminentemente teóricas apoiadas em dados secundários. Para enriquecer a análise, utilizou-se como referência o processo semelhante de desregulamentação e de abertura de mercado vivenciado pelo setor automobilístico brasileiro na década de 1990 . De forma análoga ao que ocorre hoje com a educação superior, o setor automobilístico da época possuía organizações operando com reserva de mercado e defasadas tecnologicamente.

As características atuais do setor educacional superior brasileiro estão relacionadas com as decisões tomadas no passado. Visando ampliar a oferta de vagas na educação superior que apresentava uma crise de necessidade social (SILVA JUNIOR, MARTINS, 2007) o Estado brasileiro, segundo as orientações do Banco Mundial e da UNESCO (CATANI; OLIVEIRA, 2002), flexibilizou a criação de IES e a abertura de novos cursos, sobretudo no setor privado (com e sem finalidade lucrativa). A consequência desse processo foi a transformação do setor como predominantemente privado com $89 \%$ do quantitativo de IES e $73 \%$ do total de matrículas (INEP, 2013). Porém, essas medidas não resolveram a crise de necessidade social, pois, esta necessidade não se converteu em consumo devido a fatores econômicos - a população não possuía recursos para pagar as mensalidades dos cursos nas IES privadas. O resultado foi a consolidação e a ampliação de uma crise de demanda social (SILVA JUNIOR, MARTINS, 2007) que, em parte, é visto como um dos fatores para despertar os interesses das instituições internacionais no setor educacional brasileiro.

Em outros termos, as característica atuais do setor educacional brasileiro, tipicamente privado, com mais de $80 \%$ da população sem este nível de formação por falta de recursos ou fontes de financiamentos, têm representado o contexto propício para que as pressões internacionais, via $\mathrm{OMC}$, se materializem, no sentido de cobranças pela desregulamentação e pela abertura ao mercado internacional (BORGES, 2009; SIQUEIRA, 2004; DIAS, 2003). Como consequência desse processo, a educação superior brasileira encontra-se em uma 


\section{A DESREGULAMENTAÇÃO E A ABERTURA DA EDUCAÇÃO SUPERIOR À CONCORRÊNCIA INTERNACIONAL: AMEACCA OU OPORTUNIDADE? \\ DOI: http://dx.doi.org/10.5007/1983-4535.2013v6n4p190}

encruzilhada. Por um lado adotar uma postura de defesa da educação pública sob a concepção de bem público (DIAS SOBRINHO, 2013), e de outro, ceder às pressões internacionais e transformar a educação superior em mercadoria conforme concebe a OMC (BORGES, 2009; SIQUEIRA, 2004; DIAS, 2003).

O primeiro caminho implica em investir na educação superior pública, reforçar a universidade pública e, principalmente, adotar um plano de carreira para o pessoal docente e técnico administrativo que viabilize um projeto de educação pública de qualidade e vocacionada para o longo prazo. Acredita-se que esse é o caminho mais custoso para o Estado e, por isso, o menos provável. Dada a baixa representativa da participação da educação pública na educação superior, será necessário envidar maiores esforços para reverter o quadro atual. O segundo caminho é o mais provável, pois implica em dar continuidade à politica pública traçada desde a década de 1990.

Por tudo o que foi apresentado e discutido neste ensaio, defende-se que a desregulamentação e a abertura do setor educacional superior brasileiro para a concorrência internacional, num primeiro momento, representará uma ameaça, pois as instituições brasileiras não estão preparadas para tal. Porém, num segundo momento, essa poderá vir a ser uma grande oportunidade para que a educação superior brasileira se transforme num setor qualitativamente melhor. Dependerá apenas de como o Estado brasileiro irá se posicionar diante das pressões vindas da OMC e que medidas serão tomadas em termos de políticas públicas para a educação superior, inclusive com a instituição de agências reguladoras institucionalmente fortes e alinhadas com os valores e padrões comportamentais da sociedade brasileira e não meramente voltadas para atender as demandas de organismos e organizações internacionais.

\section{REFERÊNCIAS}

BORGES, M. C. de A. A educação superior numa perspectiva comercial: a visão da Organização Mundial do Comércio. Revista Brasileira de Política e Administração da Educação - RBPAE, Recife, v.25, n.1, p. 83-91, jan./abr. 2009.

BORGES, V. M. de O. A desnacionalização do ensino superior brasileiro: educação à ordem do capital internacional. In: COLÓQUIO INTERNACIONAL SOBRE GESTÃO UNIVERSITÁRIA NAS AMÉRICAS, 12., 2012, Veracruz, Mexico. Anais... Florianópolis: INPEAU, 2012. 
BASTOS, et al. Conceito e perspectivas de estudo das organizações. In: ZANELLI, et al. (Orgs.). Psicologia,organizações e trabalho no Brasil. Porto Alegre: Artmed, 2004. p. 63 90 .

CATANI, A. M.; OLIVEIRA, J. F. de. Educação superior no Brasil: reestruturação e metamorfose das universidades públicas. Petrópolis, RJ: Vozes, 2002.

CUNHA, L. A. O público e o privado na educação superior brasileira: fronteira em desenvolvimento? In: TRINDADE, H. Universidade em ruínas: na república dos professores. 3. ed. Petrópolis, RJ: Vozes; Rio Grande do Sul: CIPEDES, 1999. p. 39-56.

CUNHA, L. A. Ensino superior e universidade no Brasil. In: LOPES, E. M. T.; FARIA FILHO, L. M.; VEIGA, C. G. (Orgs.) 500 anos de educação no Brasil. 2. ed. Belo Horizonte: Autêntica, 2000. p. 151-204. (Coleção História, 6).

DIAS, M. A. R. Comercialização do ensino superior: é possível manter a ideia de bem público? Educ. Soc., Campinas, v. 24, n. 84, p. 817-838, set. 2003.

DIAS, R. Introdução à sociologia. São Paulo: Pearson Prentice Hall, 2005.

DIAS SOBRINHO, J. Educação superior: bem público, equidade e democratização. Avaliação, Campinas; Sorocaba, SP, v. 18, n. 1, p. 107-126, mar. 2013.

DIMAGGIO, P.; POWELL, W. The iron cage revised: institutional isomorphism and collective rationality in organizational fields. American Sociological Review, v. 48, p. 147$160,1983$.

INSTITUTO BRASILEIRO DE GEOGRAFIA E ESTATÍSITCA. Censo 2010. Rio de Janeiro, IBGE, 2012. Disponível em: $<$ http://censo2010.ibge.gov.br/resultados $>$. Acesso em: 10 ago. 2013.

INSTITUTO NACIONAL DE ESTUDOS E PESQUISAS EDUCACIONAIS. Sinopse estatística de educação superior 2000. Brasília, INEP, 2001.

INSTITUTO NACIONAL DE ESTUDOS E PESQUISAS EDUCACIONAIS. Sistema de avaliação da educação superior. Brasília, INEP, 2004. Disponível em:

$<$ http://www.inep.gov.br>. Acesso em: 13 out. 2004.

INSTITUTO NACIONAL DE ESTUDOS E PESQUISAS EDUCACIONAIS. Censo da educação superior 2011: resumo técnico. Brasília, INEP, 2013.

LENZ, N.T.; ENGLEDOW, J. L. Environmental analysis: the applicability of current theory Strategic Management Journal, [S.1], v. 7, n. 4., p. 329-346, jul./aug. 1986.

LUCKESI, C. C. Avaliação da aprendizagem escolar. São Paulo: Cortez, 1994.

MASETTO, M. T. Professor universitário: um profissional da educação na atividade docente. In: MASETTO, M. T. (Org,) Docência na universidade. 4. ed. São Paulo: Papirus Editora, 1998. p. 9-25.

MINISTÉRIO DA EDUCAÇÃO. Reestruturação e expansão das universidades federais. Disponível em: <http://reuni.mec.gov.br/> Acesso 28 jul. 2013. 
ORGANISATION FOR ECONOMIC CO-OPERATION AND DEVELOPMENT.

Education at a glance 2012: OECD indicators. Paris: OECD Publishing, 2012.

REED, M. Teorização organizacional: um campo historicamente contestado. In. CALDAS, M.; FACHIN, R.; FISCHER. T. (Org.). Handbook de estudos organizacionais: modelos de análise e novas questões em estudos organizacionais. São Paulo: Atlas, 1999. v. 1, p. 61-98.

SANDRONI, P. Novíssimo dicionário de economia. São Paulo: Best Seller, 1999.

SANUELS, W. J. The presente state of institutional economics. Cambridge Journal of Economics, 19: p. 569-590, 1995.

SCHVARSTEIN, L. Psicologia social de las organizaciones: nuevos aportes. Buenos Aires: Paidós, 1995.

SILVA JUNIOR, A. da; MUNIZ, R. M. A regulamentação do ensino superior e os impactos na gestão universitária. In: COLÓQUIO INTERNACIONAL SOBRE GESTÃO

UNIVERSITÁRIA NAS AMÉRICAS, 4., 2004, Florianópolis. Anais... Florianópolis:

INPEAU, 2004.

SILVA JUNIOR, A. da; MARTINS, P. de O. Oferta e a ociosidade de vagas na educação superior brasileira: uma questão de necessidade, de demanda ou de "demanda social"?. In: ENCONTRO NACIONAL DA ASSOCIAÇÃO NACIONAL DOS CURSOS DE GRADUAÇÃO EM ADMINISTRAÇÃO - ENANGRAD, 18., 2007, Cuiabá (MT). Anais... Rio de Janeiro: ANGRAD, 2007.

SIQUEIRA, A. C. de. A regulamentação do enfoque comercial no setor educacional via OMC/GATS. Revista Brasileira da Educação. São Paulo, n. 26, p. 145-184, mai./ago. 2004.

WORLD TRADE ORGANIZATION. Services signalling conference. Geneva, Switzerland, 2008. Disponível em: <www.wto.org/english/tratop_e/dda_e/job08_93_e.doc >. Acesso em: 28 jul. 2013.

WORLD TRADE ORGANIZATION. About WTO. Geneva, Switzerland, 2013. Disponível em: <www.wto.org/english/tratop_e/dda_e/job08_93_e.doc >. Acesso em: 28 jul. 2013. 